УДК 316

ББК 60.526

DOI: 10.35211/2500-2635-2021-3-47-22-27

ФОРМИРОВАНИЕ ЗДОРОВОГО ОБРАЗА ЖИЗНИ

У СТУДЕНТОВ КАК СОЦИАЯЬНО-ВАЖНАЯ ПРОБДЕМА ГОСУДАРСТВА

\title{
FORMATION OF A HEALTHY LIFESTYLE IN STUDENTS AS A SOCIAL IMPORTANT PROBLEM OF THE STATE
}

\section{КОЧИЕВА Элина Романовна \\ Северо-Осетинский государственный университет имени К. А. Хетагурова, \\ Владикавказ, Россия \\ E-mail: georgodjiev@bk.ru}

Аннотация. Согласно представлениям современных исследователей, здоровый образ жизни, как основа развития разных сторон жизнедеятельности, характерная форма $и$ способ активного участия в общественной, профессиональной, семейной и других формах жизнедеятельности челове ка, способствует успешному выполнению социиальньх функций и профессиональных задач. В связи с этим в статье анализируется современное состояние личностномотивационной установки студентов - будущих специи листов на повьшение и реализациюо своего социиального, физического, психического и физиологического потенциила; раскрываются стержневье дефиниции, определяющзие смьсловое наполнение понятия «здоровый образ жизни» как основного фактора формирования устойчивой мотивации к активной жизненной позиции; раскрывается принциип цุехостности хичностного и общественного, нераздельности организма и окружающей среды, взаимообусловленности биологического и соииального аспектов жизнедеятельности. В формировании здорового образа жизни студентов основной проблемой выступает слабая мотивация его необходимости в их физическом, умственном, психическом и физиологическом здоровье. Проблема исследования отношения студентов к здоровому образу жизни в условиях соичи ально-политической и экономической нестабильности современного общества весьма злободневна, так как качество и успешность подготовки квалифицированньх, социиально адаптированньх специалистов, их общекультурное и профессиональное развитие зависит от сознательного выбора общественных и хичностных ценностей здорового стиля жизни. В статье доказывается тезис о том, что студенть, которые придерживаюотся здорового образа жизни, устанавливают определенное соотночение между видами деятельности (умственной, физической, досуговой и др.), хучще приспосабливаются $\kappa$ функционированию основных физиологических процессов. Важныл пунктом статьи является раздел, описьвающий статистические данные о стиле жизни студентов, а также результаты экспериментального исследования по выявлению отношения студентов Северо-Осетинского государственного университета имени К. А. Хетагурова к зооровому образу жизни в целом.

Кдючевые слова: здоровъе, здоровый образ жизни, соцзиальный аспект образа жизни, студенты, молодое поколение, стиль жизни студентов.

\section{KOCHIEVA Elina R.}

North Ossetian State University

named after K. L. Khetagurov

Vladikavkaz, Russia

E-mail: georgodjiev@bk.ru

Abstract. According to the views of modern researchers, a healthy lifestyle, as the basis for the development of various aspects of life, a characteristic form and method of active participation in social, professional, family and other forms of human life, contributes to the successful fulfillment of social functions and professional tasks. In this regard, the article analyzes the current state of the personal-motivational attitude of students - future specialists to increase and realize their social, physical, mental and physiological potential; reveals the core definitions that determine the semantic content of the concept of "healthy lifestyle" as the main factor in the formation of sustainable motivation for an active life position; reveals the principle of the integrity of the personal and social, the inseparability of the organism and the environment, the interdependence of the biological and social aspects of life. In the formation of a healthy lifestyle for students, the main problem is the weak motivation of its need for their physical, mental, mental and physiological health. The problem of studying the attitude of students to a healthy lifestyle in the conditions of socio-political and economic instability of modern society is very topical, since the quality and success of training qualified, socially adapted specialists, their general cultural and professional development depends on the conscious choice of social and personal values of a healthy lifestyle. The article proves the thesis that students who adhere to a healthy lifestyle, establish a certain relationship between the types of activity (mental, physical, leisure, etc.), better adapt to the functioning of the main physiological processes. An important point of the article is a section describing statistical data on the lifestyle of students, as well as the results of an experimental study to identify the attitude of students of the North Ossetian State University named after K.L. Khetagurov to a healthy lifestyle in general.

Keywords: health, healthy lifestyle, social aspect of lifestyle, students, young generation, student life style.

(с) Кочиева Э. Р., 2021. 
В современном обществе остро стоит проблема роста количества молодых людей с ограниченными возможностями здоровья. Как показывает анадиз раздичных источников по обозначенной проблеме, более $25 \%$ детей, поступающих в первый кдасс, имеют разного рода откдонения в здоровье (Улумбекова 2020; Улумбекова, Гиноян 2021). Ситуация усугубляется еще сильнее к окончанию школы, когда проблемы со здоровьем наблюдаются у более 80 \% выпускников общеобразовательных школ. Чего еще ожидать тогда от состояния здоровья молодых людей, поступивших в вуз? Всевозрастающий уровень заболеваемости среди данного контингента обучающихся также вызывает высокую озабоченность у медиков, психологов, педагогов, родителей и т. д.

Причину создавшейся ситуации нужно искать, прежде всего, в безграмотности населения, особенно мододежи, в вопросах здорового образа жизни, так как здоровый образ жизни определяется, прежде всего, рациональными сторонами деятельности человека: ответственностью за собственное здоровье; удовлетворенностью профессиональной деятельностью; наличием активной жизненной позиции; высоким социальным оптимизмом; достаточной физической активностью, устроенностью бытовых условий; отсутствием вредных привычек, определенной регламентацией повседневной жизнедеятельности и т. д. Среди внешних факторов, как утверждают многие ученые, основополагающим на сегодняшний день выступает здоровый образ жизни, вдияние которого на состояние здоровья составдяет окодо 55 \% (Бурьянова, Сурова 2018; Нусамиев, Хабибулдин 2019).

В качестве ведущих факторов здорового образа жизни бодьшинство исследователей рассматривает: сбалансированный режим раздичных видов деятельности, а именно: умственного, физического, трудового и т. д.; правильное питание (Хакимова, Холиева 2019); здоровый сон; систематические гигиенические процедуры; двигательная активность (Попова 2019); отсутствие вредных привычек (Ионова 2020); толерантное междичностное общение и поведение в коллективе; отсутствие беспорядочных сексуальных отношений; интересный досуг, оказывающий успокаивающее воздействие на человека.

Помимо этого, в период расцвета «мобильного виртуального мира», возникло противоречие между реальным миром и адаптационными возможностями людей к нему: увлечение разнообразными гаджетами стало частью жизнедеятельности мододого поколения, что привело к тому, что заметно снизилась двигательная активность, деформированы абсолютно все элементы здорового образа жизни, выросло количество детей и подростков с психодогическими расстройствами, ухудшилось отношение обучающихся к занятиям по физической культуре в школе и вузе. Относительно двигательной активности можно сказать также, что ее основанием выступают физическая культура и спорт. Ведущими показателями нормального физического развития дичности, как отмечают ученые, выступают мышечная сила, хорошая работоспособность, гибкость движений, пластичность тела, стойкость организма при разных нагрузках, устойчивость к разным болезням 
и т. д. Именно благодаря физической активности совершенствуются перечисленные качества дичности, ускоряется обмен веществ, укрепляется соматическое здоровье человека в целом (Нусамиев, Хабибулдин 2019). Как показывает статистика, из десяти молодых дюдей, которые твердо убеждены в том, что систематически будут заниматься спортом для поддерживания как соматического здоровья, так и физического состояния своего тела, с возрастом данный принцип соблюдают всего три-четыре (Савелов 2018).

Как известно, здоровый образ жизни предполагает организованный на принципах нравственности, активной физической и трудовой деятельности, стабильного психоэмоционального состояния, систематизации закаливающих процедур стиль жизнедеятельности (Еремин, Дегтярев 2018). Значительную часть молодого поколения составляют студенты, от состояния здоровья которых во многом зависит будущее страны: демографическое состояние; экономическая, медицинская, социально-политическая, образовательная и другие жизненно важные сферы человечества, поэтому основное внимание в статье уделено данной категории населения.

С целью выявдения вопроса, насколько студенты Северо-Осетинского государственного университета имени К. А. Хетагурова придерживаются активного образа жизни, осознают ценность своего собственного здоровья, был проведен массовый опрос студентов образовательных организаций г. Владикавказа. Опросник состоял из пяти вопросов с тремя вариантами ответов. Каждый из вопросов был нацелен на выявление оптимадьно возможных режимов двигательной активности студентов. Было опрошено 170 студентов. Следует учесть, что степень правдивости и объективности ответов испытуемых нельзя считать абсолютно точной в силу некоторых причин (например, стеснение в выражении мыслей, раздраженность и т. д.). На вопрос «Занимаетесь ли вы каким-дибо спортом?» 55 \% ответиди положительно; 15 \% испытуемых не занимаются; 30 \% - занимаются периодически. На вопрос «Вы спортивный человек?» ответили следующим образом: нет, к сожалению - 37 \% испытуемых; нет, спорт - это бессмыслица - 20 \%; да, периодами хожу в бассейн, по настроению посещаю тренажерный зал, но редко - 31 \%; да, систематически занимаюсь физическими упражнениями, но считаю, что этого недостаточно для поддерживания подноценного физического состояния - 12 \%. На вопрос «Как часто вы делаете утреннюю зарядку?» 32 \% респондентов ответили, что уделяют зарядке хотя бы 5 минут, остальные 68 \% предпочитают поспать дишние минуты. На вопрос «Считаете ди Вы себя человеком, который ведет здоровый образ жизни?» утвердительно ответили 57 \%; 30 \% ответили отрицательно; 13 \% затруднились ответить. Полученные результаты, скорее всего, свидетельствуют о том, что на сегодняшний день предпочтение здоровому образу жизни отдает небольшое количество студентов.

Проанализировав статистические данные о стиле жизни студентов, а также результаты собственного исследования по выявлению отношения студентов к здоровому образу жизни, была обнаружена неупорядоченность 
и хаотичность организации их жизнедеятельности в целом. Для изучения основных причин скептического отношения студентов к здоровому образу жизни, а также раскрытия основных направлений формирования у них навыков сознательного ведения здорового образа жизни, было проведено анкетирование. Анкета вкдючала 20 вопросов, которые были составлены с учетом внешних и внутренних факторов, влияющих на отношение студентов к здоровому образу жизни, а также к собственному здоровью. Так, например, совершенно здоровыми себя считают 32 \% испытуемых; 24 \% ответиди, что давно не наблюдадись у врачей, поэтому не могут ответить; остадьные $44 \%$ ответиди отрицательно. На вопрос, с чем они связывают отклонения в здоровье, бодьшинство ответило, что с наследственностью (40\%); другие это связывают с учебной перегрузкой (33\%); остальные $27 \%$ сослались на несоблюдение режима питания, сна и отдыха. Исследователей больше всего интересовал вопрос относительно их физкультурно-оздоровительной активности, на который большинство ответило, что не занимаются физическими упражнениями вообще (57\%); небольшой процент (11 \%) ответили иногда, и только 32 \% испытуемых ответиди утвердительно. Как следовало ожидать, на следующий вопрос «Часто ли вы болеете респираторными заболеваниями?» было много положительных ответов (48 \%). Не более утешительными были и ответы на вопрос «Имеются ли у Вас вредные привычки: курение, употребление алкоголя, психотропных веществ и т. д.?»: курят 38 \%; употребляют часто алкоголь - $12 \%$; иногда употребляют алкоголь (по особым случаям) - $17 \%$; не употребляют - $33 \%$. Что касается наркотиков, то картина здесь лучше: 4 \% признались, что употребляют легкие наркотики; $14 \%$ ответили, что 2-3 раза попробовали и на этом все закончилось; остальные 82 \% не пробовали и не собираются пробовать.

Так как в условиях современного информационного общества физическая активность мододежи вытеснена из их стиля жизни компьютерными развлечениями, то был вкдючен вопрос «Как много времени вы проводите у компьютера, вкдючая все гаджеты?»: все свободное время - 70 \% испытуемых; 11 \% - до шести часов; 12 \% - до двух часов; 17 \% - по необходимости, но не более трех часов в день. Интересным был вопрос «Дегко ли Вы впадаете в психоэмоциональное состояние?»: отрицательно ответили 64 \%; иногда 26 \%; почти никогда - 10 \%. На вопрос о неблагоприятном воздействии вредных привычек на здоровье человека, большинство ответило, что об их неблагоприятном воздействии знают, но не знают, какое именно (81 \%); остальные 19 \% перечислиди какие именно органы страдают от конкретного воздействия. И, наконец, интересно было узнать мнение студентов о пользе регулярных физических упражнений для профилактики раздичных заболеваний, а также профилактики зависимости от вредных привычек. Пользу физических нагрузок подтвердили 88 \% опрошенных, и это похвально; 12 \% считают занятия физическими упражнениями бесполезным времяпровождением.

Таким образом, в процессе анализа и интерпретации полученных результатов было выявлено отсутствие единства и целесообразности процес- 
сов самосовершенствования, саморегуляции, саморазвития и самовоспитания, сосредоточенных на оптимизации адаптивного потенциала организма, максимальной самореализации собственных врожденных сил и возможностей в общекультурном и профессиональном становлении, жизнедеятельности в целом.

Вышеперечисленные факты указывают на то, что при отсутствии строгой последовательности действий, направленных на формирование ценностного отношения к здоровому образу жизни, возникают проблемы на физическом, социальном, бытовом, личностном и профессиональном уровнях. Если раньше этот вопрос поднимался лишь при обследовании у врача, то сегодня на каждом шагу слышны призывы к здоровому образу жизни во всех средствах массовой информации. Главным образом, это связано с тем, что низкий уровень двигательной активности не обеспечивает полноценное функционирование организма человека (Амирова 2018), что приводит, как правило, к снижению качества работоспособности, уменьшению двигательных реакций, ухудшению координации движений и т. д.

Что же подразумевает понятие «здоровый образ жизни»? Исходя из концепции жизнедеятельности личности, направленной на укрепление и сохранение здоровья, феномен «здоровый образ жизни» можно рассматривать через призму физиологических адаптационных возможностей личности, направленных на совершенствование психического, физиологического, физического и эмоционального состояния человека (Шиганов 2020).

Образ жизни некоторые исследователи рассматривают как социальную категорию, отвечающую не только за присутствие или отсутствие вредных привычек, но и определяющую уровень производства и потребления товаров и услуг, качества жизнедеятельности, культуры, доступность образовательных, медицинских и социальных услуг, моральный настрой человека и т. д. Здоровье - состояние физического, психического и социального благополучия человека, при котором отсутствуют заболевания, а также расстройства функций органов и систем организма» (Судакова, Сабетов 2018).

Таким образом, можно сделать вывод о том, что родь здорового образа жизни в сочетании с разнообразной и разносторонней физкультурнооздоровительной деятельностью велика в социальной политике сферы образования. Поэтому формирование здорового образа жизни у студентов будущих специалистов - существенная социально-значимая задача общества и государства. Также усиление социальной стимуляции студентов должно проходить через ряд мероприятий, проводимых в учебных заведениях. К ним можно отнести проведение конкурсов и спортивных эстафет; знакомство с научно-обоснованными санитарно-гигиеническими нормативами, направленными на укрепление и сохранение здоровья. Результаты исследования убедили в том, что овладевая высоким уровнем здорового образа жизни, студент начинает понимать и анадизировать собственные недостатки, глубже осмысливать свое физическое, психическое, соматическое и физиологическое состояния, стараясь изменить их в лучшую сторону. 


\section{ИСПОЛЬЗОВАННЫЕ ИСТОЧНИКИ}

1. Амирова, А. С. Конкурентоспособность - через формирование здорового образа жизни / А. С. Амирова // Профилактика зависимостей. - 2018. - № 1 (13). - С. 120-125.

2. Бурьянова, А. А. Формирование здорового образа жизни как социально-педагогическая проблема учащейся молодежи / А. А. Бурьянова, К. Р. Сурова // Проблемы высшего образования. - 2018. - № 1. - С. 63-64.

3. Еремин, М. В. Формирование понятия необходимости здорового образа жизни среди студентов / М. В. Еремин, С. А. Дегтярев // Физическое воспитание и детско-юношеский спорт. - 2018. - № 3/4. - С. 53-54.

4. Ионова, О. В. Вдияние физкультурно-оздоровительной деятельности на формирование здорового образа жизни студенческой мододежи / О. В. Ионова // Известия высших учебных заведений. Поволжский регион. Общественные науки. - 2020. - № 3 (55). - С. 71-79.

5. Нусамиев, Н. Ш. Формирование здорового образа жизни студентов / Н. Ш. Нусамиев, А. Б. Хабибуллин // Наука и образование: новое время. - 2019. - № 1 (30). - С. 706-709.

6. Попова, Н. В. Влияние средств физической культуры на формирование здорового образа жизни студенческой молодежи / Н. В. Попова // Colloquium-journal. - 2019. - № 6-9 (30). C. 72-73.

7. Савелов, Н. И. Спорт в жизни человека как формирование здорового образа жизни / Н. И. Савелов // Азбука образовательного пространства. - 2018. - № 1 (2). - С. 51-53.

8. Судакова, М. В. Формирование здорового образа жизни как психолого-педагогическая проблема / М. В. Судакова, Э. Г. Сабетов // Наука и образование. - 2018. - Т. 1. - № 1. - С. 16.

9. Тимохина, А. С. Формирование ценностей здорового образа жизни / А. С. Тимохина, Е. А. Волкова // Аллея науки. - 2018. - Т. 5. - № 4 (20). - С. 916-919.

10. Улумбекова, Г. Э. Программа неотложных мер в здравоохранении РФ для выхода из системного кризиса / Г. Э. УАумбекова // ОРГЗДРАВ: новости, мнения, обучения. Вестник ВШОУ3. - 2020. - Т. 6. - № 1 (19). - С. 4-16.

11. Улумбекова, Г. Э. Рейтинг эффективности систем здравоохранения регионов РФ в 2019 г. / Г. Э. УАумбекова, А. Б. Гиноян // ОРГЗДРАВ: новости, мнения, обучения. Вестник ВШОУ3. - 2021. - Т. 7. № 1 (23). С. 4-16.

12. Хакимова, Ф. Т. Внедрения инновационных технологий в формирование здорового образа жизни студентов / Ф. Т. Хакимова, Н. Х. Холиева // Наука, техника и образование. 2019. - № 4 (57). - C. 102-104.

13. Шиганов, В. А. Влияние физических упражнений на формирование здорового образа жизни / В. А. Шиганов // Наука XXI века: актуальные направления развития. - 2020. - № 1-2. C. 270-274.

14. Показатели здоровья детей и подростков в России. - Режим доступа: URL: https://www.vshouz.ru/journal/2016-god/pokazateli-zdorovya-detey-i-podrostkov-v-rossii (дата обращения 25.05.2021 г.). 